\title{
Quantitative analysis of surface sites on carbon dots and their interaction with metal ions by potentiometric titration method
}

\author{
Zhe Wang ${ }^{\mathrm{a}, \mathrm{b}}$, Yu Xie ${ }^{\mathrm{c}}$, Zhen Lei ${ }^{\mathrm{a}}$, Yuexiang Lu ${ }^{*}$, Guoyu Wei ${ }^{\mathrm{b}}$, Shuang Liu ${ }^{\mathrm{b}}$, Chao Xu ${ }^{\mathrm{b}}$, Zhicheng
} Zhang $^{\mathrm{d}}$, Xiangke Wang, ${ }^{\mathrm{a}, \mathrm{e}}$, Linfeng Rao*d, Jing Chen ${ }^{* \mathrm{~b}}$

a. The MOE Key Laboratory of Resource and Environmental System Optimization, School of Environment and Chemical Engineering, North China Electric Power University, Beijing 102206, P.R. China

b. Institute of Nuclear and New Energy Technology, Collaborative Innovation Center of Advanced Nuclear Energy Technology, Beijing Key Lab of Radioactive Waste Treatment, Tsinghua University, Beijing 100o84, P.R. China c. Department of Environmental Engineering and Earth Sciences, Clemson University, 342 Computer Court, Anderson, South Carolina 29625, United States

d. Chemical Sciences Division, Lawrence Berkeley National Laboratory, 1 Cyclotron Rd., Berkeley, California 94720, United States

e. Hebei Key Lab of Power Plant Flue Gas Multi-Pollutants Control, Department of Environmental Science and Engineering, North China Electric Power University, Baoding 071003, P.R. China

*Email: luyuexiang@mail.tsinghua.edu.cn

*Email: lrao@lbl.gov

*Email: jingxia@mail.tsinghua.edu.cn 


\section{Table of Contents}

1. Results and discussion: Characterization of CDs

2. Figure S1 Characterizations of ArgCDs and GlyCDs. TEM images of (a) ArgCDs and (d) GlyCDs. Size distribution of (b) ArgCDs and (e) GlyCDs counting 50 particles from TEM images. Fluorescent spectra of (c) ArgCDs and (f) GlyCDs excited by various wavelength S-4

3. Figure S2 (a) FT-IR analysis of ArgCDs and GlyCDs. XPS analysis of (b) ArgCDs and (c) GlyCDs, inset was the $\mathrm{C} 1 \mathrm{~s}$ peak analysis.

4. Table S1 XPS analysis of ArgCDs and GlyCDs (element content).... S-5

5. Table S2 XPS analysis of ArgCDs and GlyCDs (C1s peak analysis) $\ldots \ldots \ldots \ldots \ldots \ldots \ldots \ldots \ldots \ldots . . .5$

6. Figure $\mathrm{S} 3$ The $\mathrm{p} K_{\mathrm{a}}$ modeling results of the surface sites on (a) ArgCDs and (b) GlyCDs with various concentrations by the Hyperquad program S-6

7. Figure $\mathrm{S} 4 \mathrm{The}$ species distribution of $\mathrm{Fe}(\mathrm{III})$ at various concentrations of $\mathrm{Fe}(\mathrm{III})$ and ArgCDs. (a) The concentration of $\mathrm{Fe}(\mathrm{III})$ of the five graphics were $0.01,0.1,1,10,100 \mathrm{mM}$ with a fixed $1 \mathrm{mM}$ of $\mathrm{ArgCDs}$, respectively. (b) The concentration of ArgCDs of the five graphics were 100, 10, 1, 0.1, $0.01 \mathrm{mM}$ with a fixed $1 \mathrm{mM}$ of $\mathrm{Fe}(\mathrm{III})$, respectively.... S-6

8. Figure S5. The stability constants modeling results using Hyperquad program of the GlyCDs-U(VI) system with different concentration of (a) GlyCDs and (b) U(VI)

9. Table S3 Stability constants calculated by Hyperquad program for the surface sites of GlyCDs with U(VI)

10. Figure S6. The species distribution of U(VI) in the GlyCDs-U(VI) system as the pH changing from 2 to 8. 


\section{Results and discussion}

\section{Characterization of CDs}

The carbon dots were synthesized through a facile hydro-thermal method with citric acid and amino acids as raw materials. The morphology and structure of ArgCDs and GlyCDs were characterized via various analysis. As estimated from the TEM image (Figure S1a and S1d), the CDs had a uniform dispersion with a mean particle diameter of $3.3 \mathrm{~nm}$ for ArgCDs and $2.5 \mathrm{~nm}$ for GlyCDs (Figure S1b and S1e). And most particles are observed to be amorphous carbon particles without any lattice fringes. In the fluorescent spectra (Figure S1c and S1f), the peaks red-shifted with the increasing excitation wavelength from $300 \mathrm{~nm}$ to $400 \mathrm{~nm}$. This excitation-dependent behavior was normal for most of the carbon dots and could attribute to the surface state affecting the band gap of CDs. The strongest peak of the two kinds of CDs both centered at around $420 \mathrm{~nm}$ when excited at $340 \mathrm{~nm}$. By employing quinine sulfate as a reference, the quantum yield (QY) was calculated to be $21 \%$ and $12 \%$ for $\operatorname{ArgCDs}$ and GlyCDs, respectively.

The surface functional groups of CDs were identified through FT-IR spectra (Figure S2a). The broad peak at $3000-3500 \mathrm{~cm}^{-1}$ for ArgCDs and GlyCDs were allocated to the stretching vibrations of O-H and N-H. The band at $1710 \mathrm{~cm}^{-1}$ on the line of $\operatorname{ArgCDs}$ was assigned to the vibration of $\mathrm{C}=\mathrm{O}$. And it was involved in the stronger peak at $1660 \mathrm{~cm}^{-1}$ on the line of GlyCDs, which should be attribute to the higher content of the carboxyl groups. The peaks at $1570 \mathrm{~cm}^{-1}$ for $\delta(\mathrm{N}-\mathrm{H})$ and $1400 \mathrm{~cm}^{-1}$ for $v(\mathrm{C}-\mathrm{NH})$ indicated the successfully adulterating of nitrogen atoms into the CDs. And it was clear that the adsorption intensity for ArgCDs was much stronger than GlyCDs, which was agreed well with the property of the raw materials. The chemical 
compositions and surface groups of CDs were further investigated by XPS. From Figure S2b and S2c, three peaks at $284.3(\mathrm{C} 1 \mathrm{~s}), 399.9(\mathrm{~N} 1 \mathrm{~s})$, and $531.4 \mathrm{eV}(\mathrm{O} 1 \mathrm{~s})$ were clearly observed on both ArgCDs and GlyCDs. The nitrogen content on ArgCDs was evidently higher than GlyCDs in Table S1. The further analysis of C1s peaks confirmed the presence of $\mathrm{C}-\mathrm{C}, \mathrm{C}-\mathrm{N}$ and $\mathrm{C}-\mathrm{O}$ chemical bonds on $\mathrm{CDs}$ in Table S2, which was consistent with the FT-IR analysis. The existing of these functional groups improved the solubility and stability in aqueous systems and accounted for the following interactions with metal ions.

a)

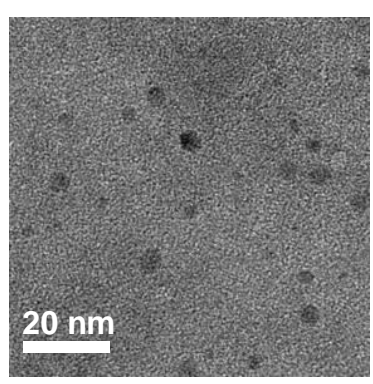

d)

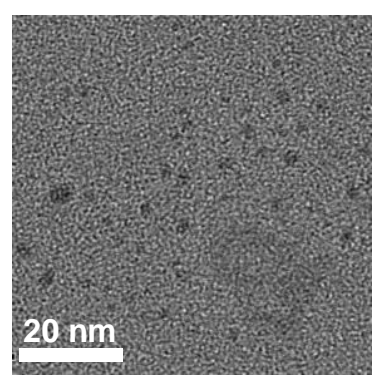

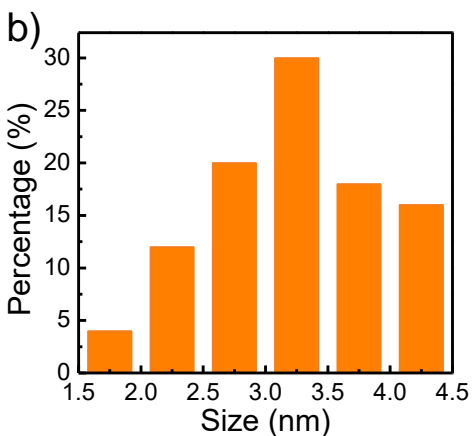

e)

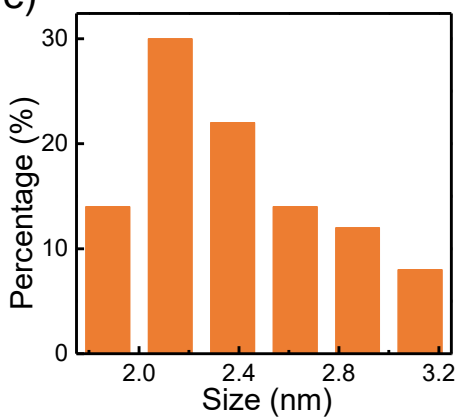

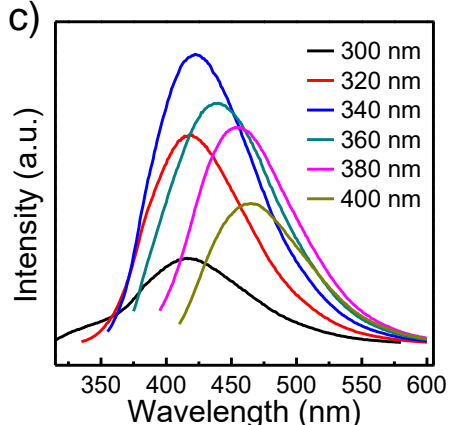

f)

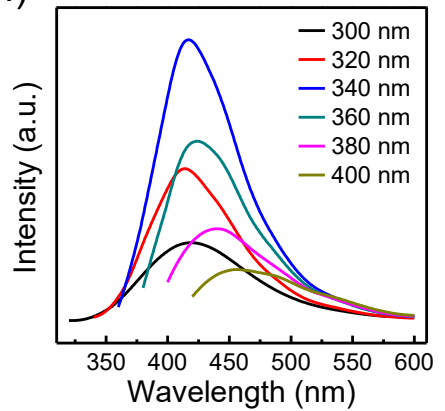

Figure S1. Characterizations of ArgCDs and GlyCDs. TEM images of (a) ArgCDs and (d) GlyCDs. Size distribution of (b) ArgCDs and (e) GlyCDs counting 50 particles from TEM images. Fluorescent spectra of (c) ArgCDs and (f) GlyCDs excited by various wavelength. 

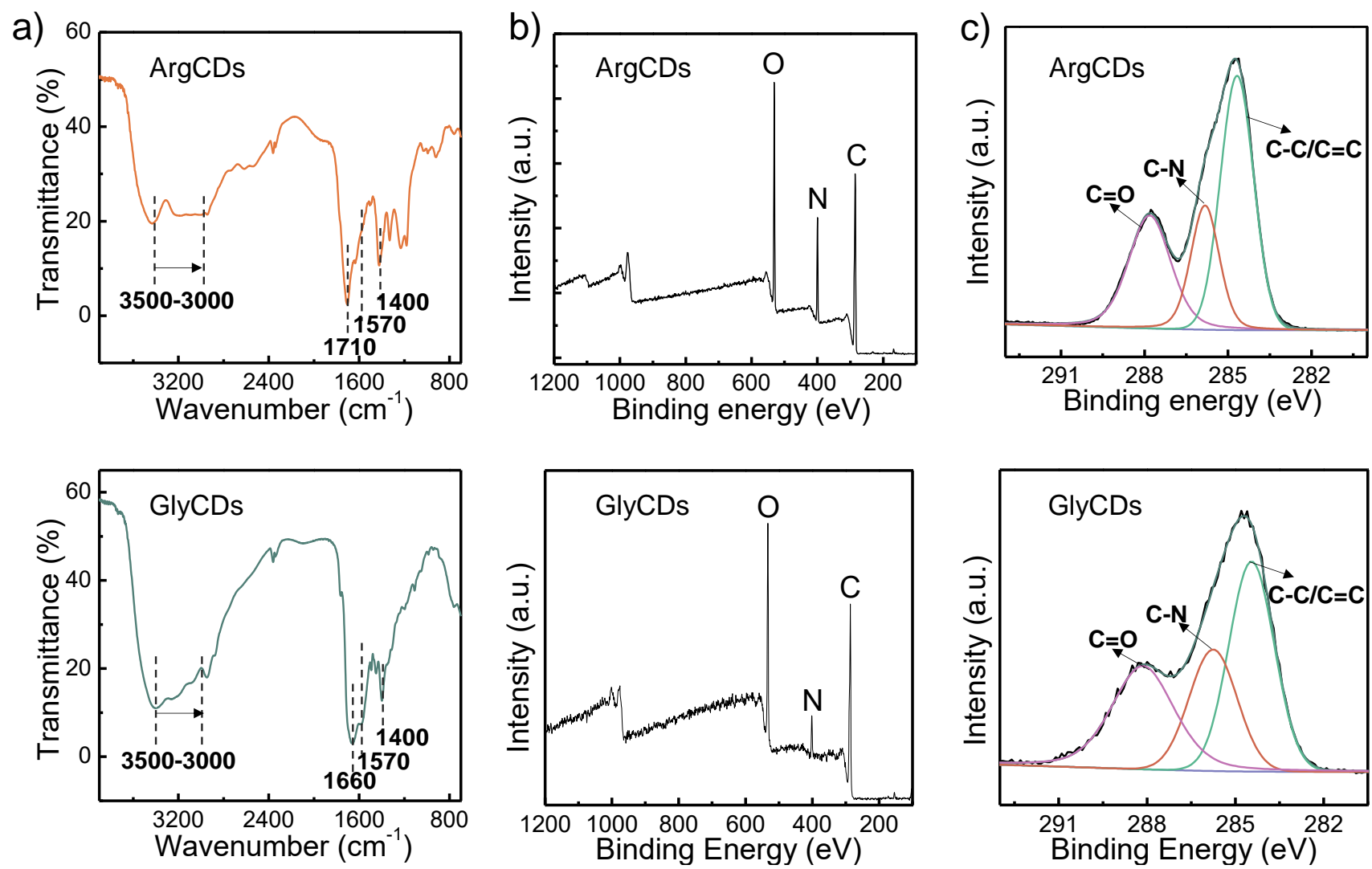

Figure S2. (a) FT-IR analysis of ArgCDs and GlyCDs. (b) XPS analysis and (c) the C1s peak analysis of ArgCDs and GlyCDs.

Table S1 XPS analysis of ArgCDs and GlyCDs (element content)

\begin{tabular}{cccc}
\hline & C1s $(\%)$ & N1s $(\%)$ & O1s $(\%)$ \\
\hline ArgCDs & 58.65 & 18.99 & 22.36 \\
GlyCDs & 66.76 & 7.11 & 26.13 \\
\hline
\end{tabular}

Table S2 XPS analysis of ArgCDs and GlyCDs (C1s peak analysis)

\begin{tabular}{cccc}
\hline & C-C/C=C & Oxygenated Carbon & Nitrous Carbon \\
\hline \multirow{2}{*}{ ArgCDs } & $284.7 \mathrm{eV}$ & $285.8 \mathrm{eV}$ & $287.8 \mathrm{eV}$ \\
& $47.8 \%$ & $21.9 \%$ & $30.3 \%$ \\
\multirow{2}{*}{ GlyCDs } & $284.4 \mathrm{eV}$ & $285.7 \mathrm{eV}$ & $288.1 \mathrm{eV}$ \\
& $41.8 \%$ & $25.5 \%$ & $32.7 \%$ \\
\hline
\end{tabular}



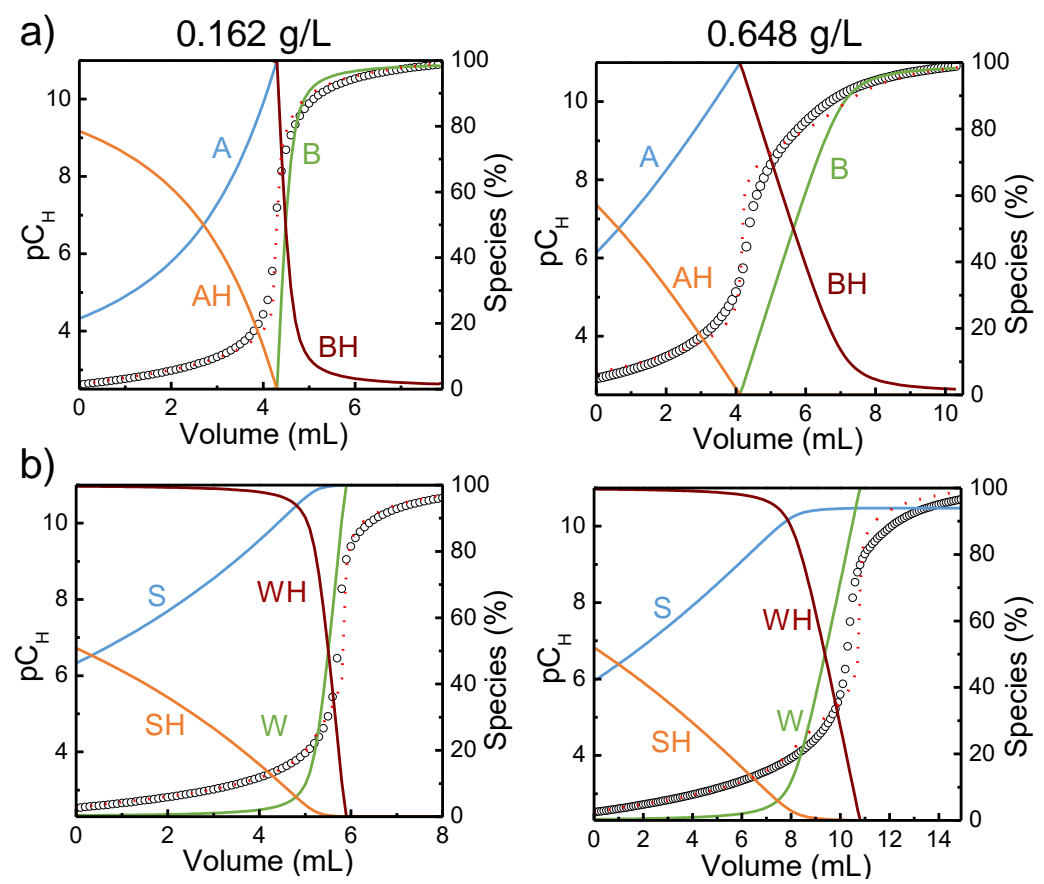

Figure S3. The $\mathrm{p} K_{\mathrm{a}}$ modeling results of the surface sites on (a) ArgCDs and (b) GlyCDs with various concentrations by the Hyperquad program.
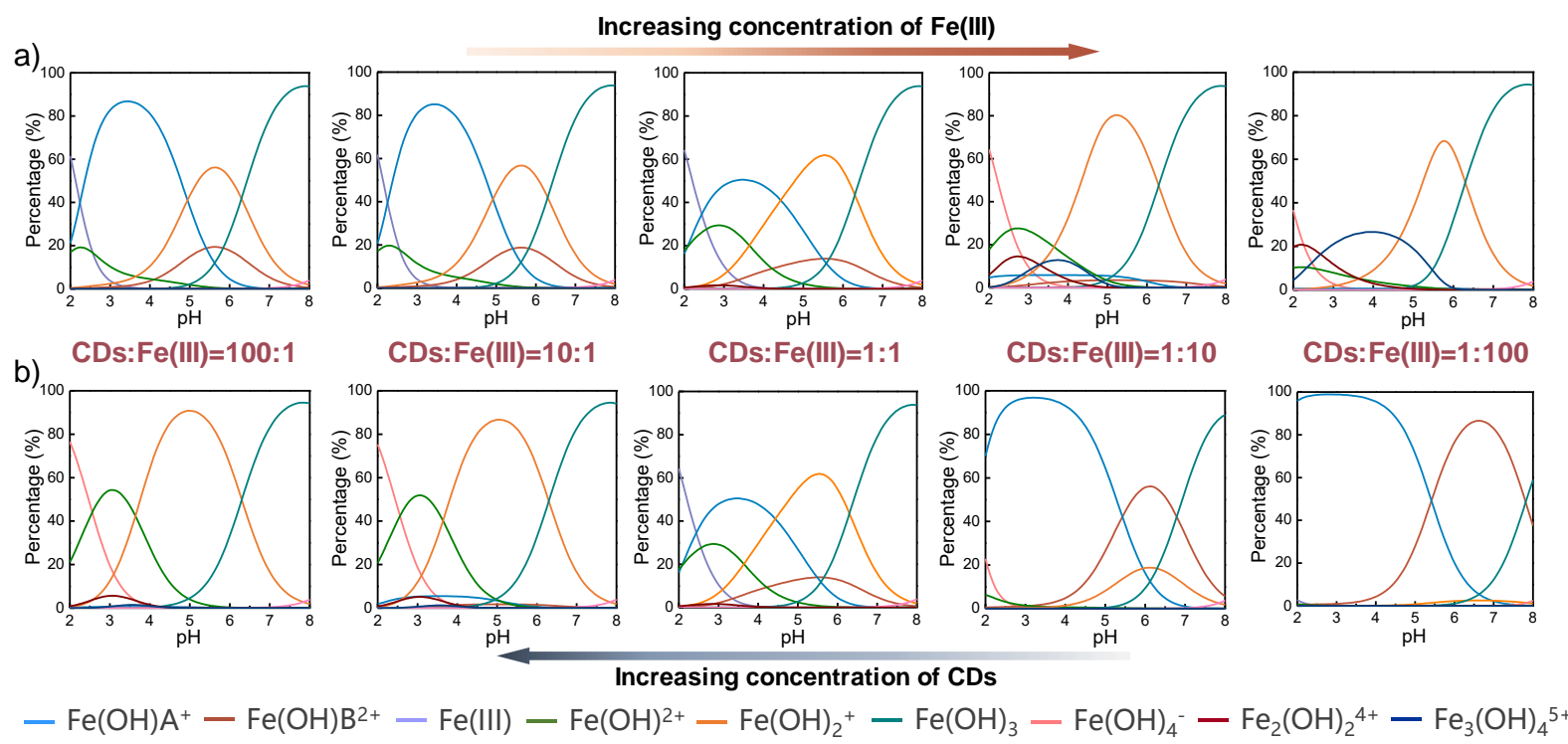

Figure S4. The species distribution of $\mathrm{Fe}(\mathrm{III})$ at various concentrations of $\mathrm{Fe}(\mathrm{III})$ and $\mathrm{ArgCDs}$. (a) The concentration of $\mathrm{Fe}(\mathrm{III})$ of the five graphics were $0.01,0.1,1,10,100 \mathrm{mM}$ with a fixed $1 \mathrm{mM}$ of ArgCDs, respectively. (b) The concentration of ArgCDs of the five graphics were 100,10, 1, 0.1, $0.01 \mathrm{mM}$ with a fixed $1 \mathrm{mM}$ of $\mathrm{Fe}(\mathrm{III})$, respectively. 


\section{The interaction between GlyCDs and U(VI)}

Figure S5 presented the representative potentiometric titration modeling results of the complexation of U(VI) with GlyCDs. Various concentration of GlyCDs and $\mathrm{U}(\mathrm{VI})$ were carried out in the titration experiments to obtain a more reliable result. The experiment data were best fitted with the model including the formation of three $\mathrm{U}(\mathrm{VI})$ hydrolysate, $\mathrm{UO}_{2}(\mathrm{SH})^{2+}, \mathrm{S}\left(\mathrm{UO}_{2}\right) \mathrm{W}, \mathrm{W}\left(\mathrm{UO}_{2}\right) \mathrm{OH}$. Table $\mathrm{S} 3$ listed the calculated stability constants for these complexes. From Figure S5a, because of the higher concentration of GlyCDs, more surface sites were provided for linking with $\mathrm{U}(\mathrm{VI})$, leading to the boosting percentage content of $\mathrm{UO}_{2}(\mathrm{SH})^{2+}$, $\mathrm{S}\left(\mathrm{UO}_{2}\right) \mathrm{W}$ and $\mathrm{W}\left(\mathrm{UO}_{2}\right) \mathrm{OH}$ species, as well as the reducing of hydrolyzed species of $\mathrm{U}(\mathrm{VI})$. As the concentration of $\mathrm{U}(\mathrm{VI})$ increased, an opposite phenomenon was observed for the complexes and the hydrolytic species (Figure S5b).
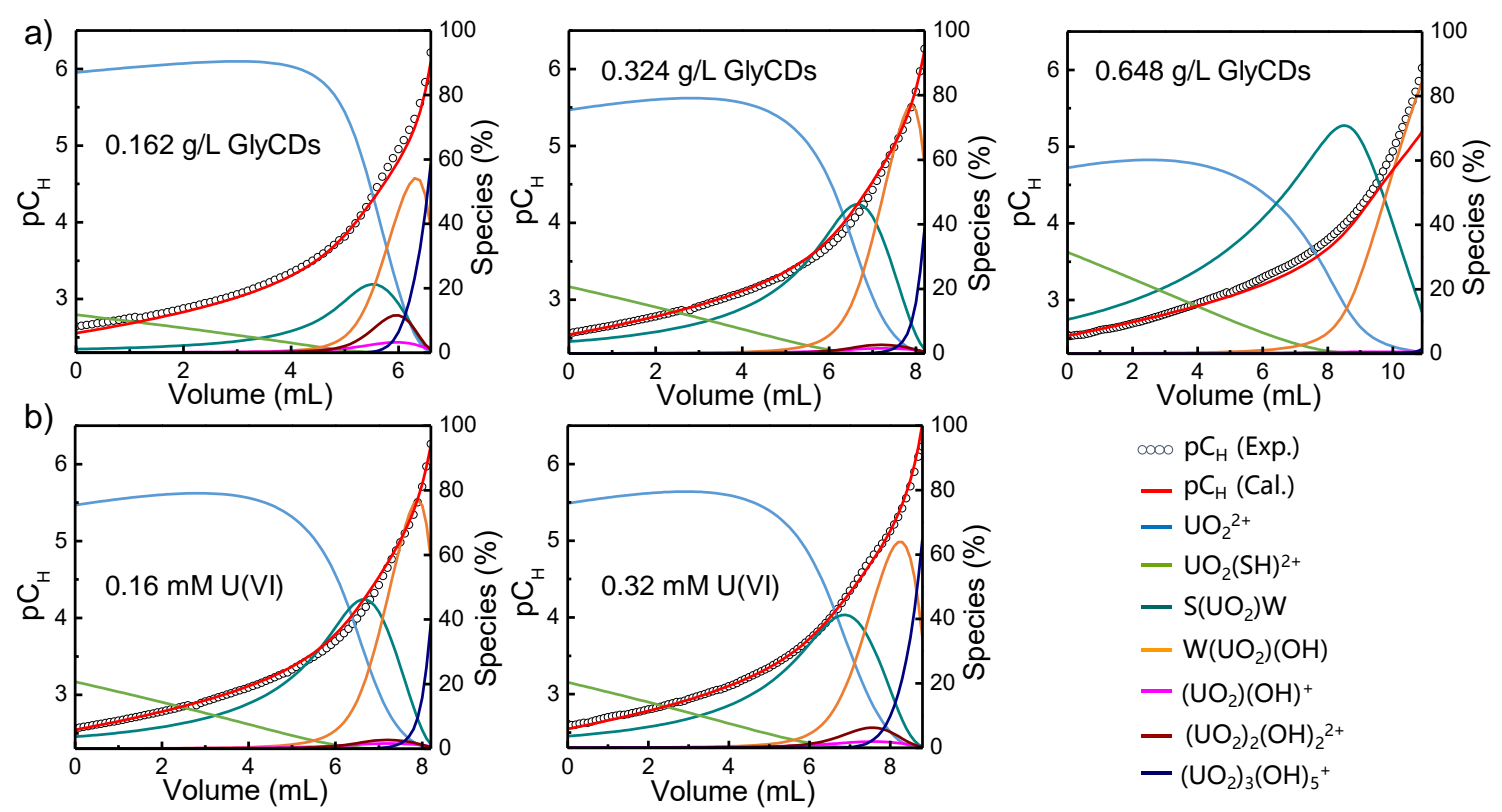

Figure S5. The stability constants modeling results using Hyperquad program of the GlyCDs-U(VI) system with different concentration of (a) GlyCDs and (b) U(VI). 
Table S3 Stability constants calculated by Hyperquad program for the surface sites of GlyCDs with U(VI).

\begin{tabular}{ll}
\hline Protonation equilibria & $\log K$ \\
\hline $\mathrm{H}^{+}+\mathrm{S}^{-} \rightarrow \mathrm{SH}$ & $2.61 \pm 0.06$ \\
$\mathrm{H}^{+}+\mathrm{W}^{-} \rightarrow \mathrm{WH}$ & $4.98 \pm 0.06$ \\
$\mathrm{SH}+\mathrm{UO}_{2}^{2+} \rightarrow\left(\mathrm{UO}_{2}\right)(\mathrm{SH})^{2+}$ & $5.00 \pm 0.27$ \\
$\mathrm{~S}^{-}+\mathrm{UO}_{2}^{2+}+\mathrm{W}^{-} \rightarrow \mathrm{S}\left(\mathrm{UO}_{2}\right) \mathrm{W}$ & $7.20 \pm 0.05$ \\
$\mathrm{~W}^{-}+\mathrm{UO}_{2}^{2+}+\mathrm{OH}^{-} \rightarrow \mathrm{W}\left(\mathrm{UO}_{2}\right)(\mathrm{OH})$ & $13.43 \pm 0.03$ \\
$\mathrm{UO}_{2}^{2+}+\mathrm{OH}^{-} \rightarrow\left(\mathrm{UO}_{2}\right)(\mathrm{OH})^{+}$ & 8.12 \\
$2 \mathrm{UO}_{2}^{2+}+2 \mathrm{OH}^{-} \rightarrow\left(\mathrm{UO}_{2}\right)_{2}(\mathrm{OH})_{2}^{2+}$ & 21.55 \\
$3 \mathrm{UO}_{2}^{2+}+5 \mathrm{OH}^{-} \rightarrow\left(\mathrm{UO}_{2}\right)_{3}(\mathrm{OH})_{5}^{+}$ & 52.13 \\
\hline
\end{tabular}

To make the distribution of the complexes in the suspension more straightforward, the curves of different complexes of $\mathrm{U}(\mathrm{VI})$ in the range of $\mathrm{pH}=2$ to $\mathrm{pH}=8$ were drawn in Figure $\mathrm{S} 6$. At the initial $\mathrm{pH}=2$, lots of $\mathrm{H}^{+}$ occupied the surface site of GlyCDs and about $83 \% \mathrm{U}(\mathrm{VI})$ existed as uranyl $\left(\mathrm{UO}_{2}^{2+}\right)$. Only a little of site $\mathrm{SH}$ complexed with uranyl to form the $\mathrm{UO}_{2}(\mathrm{SH})^{2+}$ species. With the slowly rising $\mathrm{pH}$ of the system, the surface sites began to expose and uranyl might combine with site $\mathrm{S}$ and $\mathrm{W}$ to form $\mathrm{S}\left(\mathrm{UO}_{2}\right) \mathrm{W}$. It was from $\mathrm{pH}=3.5$, the uranyl began to hydrolyze to $\left(\mathrm{UO}_{2}\right)(\mathrm{OH})^{+}$and $\left(\mathrm{UO}_{2}\right)_{2}(\mathrm{OH})_{2}^{2+}$ species. The $\mathrm{W}\left(\mathrm{UO}_{2}\right)(\mathrm{OH})$ complex was also observed to start. As the sustainable growth of the $\mathrm{pH}$, the disappeared of $\mathrm{UO}_{2}(\mathrm{SH})^{2+}$, the peak of $\mathrm{S}\left(\mathrm{UO}_{2}\right) \mathrm{W}$ at $\mathrm{pH}=4.2$ and the peak of $\mathrm{W}\left(\mathrm{UO}_{2}\right)(\mathrm{OH})$ at $\mathrm{pH}=5.2$ were discovered successively. Then the content of $\mathrm{W}\left(\mathrm{UO}_{2}\right)(\mathrm{OH})$ reduced, along with the growth amount of $\left(\mathrm{UO}_{2}\right)_{3}(\mathrm{OH})_{5}^{+}$, of which turned into the main species in the suspension at $\mathrm{pH}=8$. 


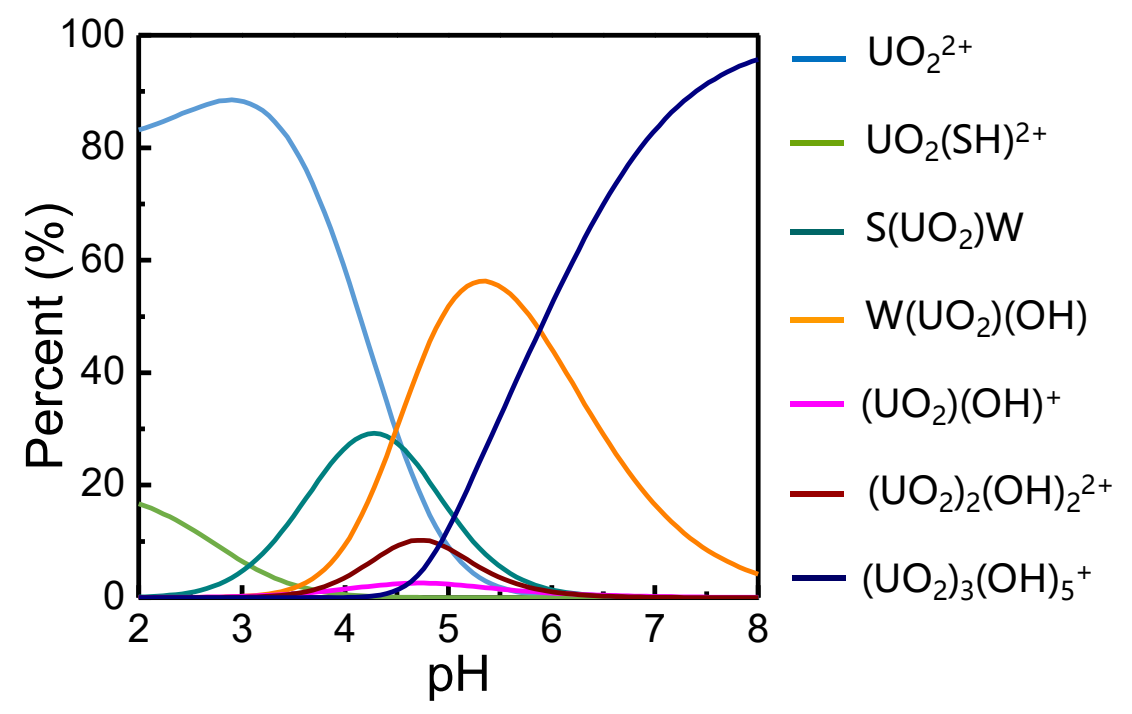

Figure S6. The species distribution of U(VI) in the GlyCDs-U(VI) system as the pH changing from 2 to 8. 